\title{
PRODUÇÃO ACADÊMICA BRASILEIRA SOBRE AVALIAÇÃO EM EDUCAÇÃO INFANTIL: PRIMEIRAS APROXIMAÇÕES
}

\section{RESUMO}

Este trabalho busca contribuir com o debate sobre politica de avaliação em educação infantil no Brasil a partir das últimas modificações da legislação e das normatizações federais sobre o tema, levando em conta as polêmicas em torno das práticas atuais de avaliação da primeira etapa da educação básica. É finalidade do estudo mapear e examinar a produção acadêmica brasileira dedicada a esse tema no período de 1997 a 2012. 0 corpus empírico da pesquisa circunscreve-se a teses e dissertações cadastradas no banco de teses da Capes e a artigos de periódicos incluídos na plataforma SciELO, no portal de periódicos da Capes e no portal Educ@.

\footnotetext{
PALAVRAS-CHAVE AVALIAÇÃO • EDUCAÇÃO INFANTIL • SISTEMATIZAÇÃO DO CONHECIMENTO • POLÍTICAS PÚBLICAS EM EDUCAÇÃO.
} 


\section{RESUMEN}

Este trabajo busca contribuir con el debate sobre politica de evaluación en educación infantil en Brasil a partir de las últimas modificaciones de la legislación y de las normalizaciones federales sobre el tema, teniendo en cuenta las polémicas en torno a las actuales prácticas de evaluación de la primera etapa de la educación básica. Es finalidad del estudio mapear y examinar la producción académica brasileña dedicada a este tema en el periodo de 1997 a 2012. El corpus empírico de la investigación se circunscribe a tesis y disertaciones registradas en el banco de tesis de Capes y a artículos de revistas incluidos en la plataforma SciELO, en el portal de revistas de Capes y en el portal Educ@.

PALABRAS CLAVE EVALUACIÓN • EDUCACIÓN INFANTIL • SISTEMATIZACIÓN DEL CONOCIMIENTO • POLÍTICAS PÚBLICAS EN EDUCACIÓN.

\section{ABSTRACT}

This study attempts to contribute to the debate about evaluation policy in early childhood education in Brazil, from the latest modifications in federal legislation and standardization thereto. It takes into account the controversies around the current practices of evaluation in the first stage of basic education. The purpose of the study is to outline and examine Brazilian academic production, dedicated to this end, during the period from 1997 to 2012. The empirical corpus of the study includes the theses and dissertations registered in the Capes database of theses and also periodical articles included in the SciELO platform, from the Capes periodical portal and the Educ@ portal.

KEYWORDS EVALUATION • EARLY CHILDHOOD EDUCATION • SYSTEMATIZATION OF KNOWLEDGE • PUBLIC POLICIES IN EDUCATION. 


\section{INTRODUÇÃO}

Propomos discutir o tema da avaliação na educação infantil na perspectiva de entendê-la como integrante/partícipe de um debate mais amplo sobre política e qualidade da educação, tendo como princípio orientador a avaliação como processo formativo e democrático.

É necessário sublinhar que o debate acerca da avaliação em educação infantil remete, necessariamente, ao tema da avaliação educacional e, no Brasil, essa é uma área bastante investigada e com uma produção de grande relevância. Temos ciência de que essa literatura vasta e consistente, que se debruça sobre a análise da produção acerca da temática da avaliação educacional no Brasil e de seus usos, destaca-se a partir dos anos 1970 - período que corresponde à organização dos programas de pós-graduação em educação no país. Tal produção voltava-se principalmente à avaliação da aprendizagem, tendo como foco a etapa de ensino correspondente ao atual ensino fundamental.

Os anos de 1980 são marcados pelo debate político em torno da transição democrática, e as pesquisas sobre o tema 
refletem a preocupação com a escola, os mecanismos de promoção e retenção das crianças e jovens, os programas curriculares, a relação entre instituição escolar e Estado, entre outras questões. Diante desse cenário, como apontado pela pesquisadora Sandra Zákia Sousa (1995), na segunda metade dos anos 1980, acena-se para a construção de concepções que se contrapõem à visão tecnicista de avaliação, presente em pesquisas das décadas de 1960 e 1970 . E, nesse sentido, engendram-se novas perspectivas para a teoria de avaliação da aprendizagem, com foco em dimensões intrínsecas ao processo pedagógico, compreendendo-se a realidade escolar como projeto educacional e social com vistas ao redirecionamento das intervenções educativas. Em relação ao campo específico da educação infantil, é também a partir da segunda metade dos anos de 1980 que se encontram os primeiros estudos que abordam a avaliação, ainda no bojo de uma discussão mais ampla sobre outros temas e outros níveis de ensino.

A partir da década de 1990, surge o paradigma da avaliação qualitativa na produção acadêmica, ainda com pouca densidade conceitual. Em relação ao educando, para além da dimensão cognitiva, passa-se a considerar os aspectos social e afetivo, os valores, as motivações e até mesmo sua história de vida. Como afirmam Barretto et al. (2001), a ênfase recai agora nas variáveis de processo, mais do que no resultado da educação; e a avaliação é pleiteada como dialógica e dialética, voltada para a transformação, tanto no plano pessoal como no social:

Reforça-se o eixo da avaliação centrado nas condições em que é oferecido o ensino, na formação do professor e de suas condições de trabalho, no currículo, na cultura e organização da escola, bem como na postura dos atores educacionais em seu conjunto, deixando de girar exclusivamente em torno do aluno. (BARRETTO et al., 2001, p. 55)

Nas produções acadêmicas dos anos 2000, adquire corpo a discussão sobre a centralidade que a avaliação educacional passa a ter na configuração dos sistemas de ensino brasileiros a partir dos anos 1990, principalmente com a proposta de avaliação externa em larga escala. Inúmeras têm sido as 
1 Sistema criado em 1990 pelo Ministério da Educação (MEC) para aferir o rendimento dos alunos do ensino fundamental e médio por meio de uma matriz de referência curricular formulada com base no ensino por competência, que passa a ser referenciada mais tarde nos parâmetros curriculares nacionais.

2 Avaliação censitária, de adesão voluntária, das redes estaduais municipais, instituída pelo MEC em 2005. Verifica o desempenho de crianças e jovens no último ano das séries iniciais e no último ano das séries finais do ensino fundamental. Possibilita situar os resultados da escola em relação à sua rede e à média nacional

3 Avaliação instituída pelo MEC em 2007, de adesão voluntária, das redes de ensino municipal e estadual, para verificar o desempenho de crianças egressas do 10 ano do ensino fundamental em dois momentos ao longo do $2^{\circ}$ ano.

4 Índice criado em 2007 pelo Instituto Nacional de Estudos e Pesquisas Educacionais (Inep). Combina dados de rendimento dos alunos com a capacidade demonstrada pela escola de manter 0 conjunto de seus alunos estudando e com bom aproveitamento. críticas à lógica intrínseca às propostas de avaliação adotadas no país (BARRETTO, 2012; SOUSA; OLIVEIRA, 2003). Sousa e Oliveira evidenciam o risco de propostas de avaliação como o Sistema de Avaliação da Educação Básica (Saeb), ${ }^{1}$ a Prova Brasil, ${ }^{2}$ a Provinha Brasil, ${ }^{3}$ assim como o Índice de Desenvolvimento da Educação Básica (Ideb) ${ }^{4}$ - se tornarem exclusivamente mecanismos de controle e competitividade, associados ou não a estímulos financeiros. Para os autores, essas propostas podem resultar na naturalização das desigualdades educacionais e sociais, na atribuição de mérito com fins classificatórios "que apoiam a hierarquização de unidades federadas, de instituições ou de alunos”, e não na melhoria da qualidade, como em tese se pretende (SOUSA; OLIVEIRA, 2003, p. 889). Eles ressalvam o fato de ainda serem escassos, no Brasil, estudos que visem a identificar os impactos já produzidos por tais avaliações nos sistemas e instituições de ensino.

Considerando os poucos trabalhos acerca dos possíveis impactos das avaliações externas e dos usos de seus resultados, é importante destacar uma pesquisa realizada por Brooke e Cunha (2011) sobre os sistemas de avaliação de cinco estados brasileiros. Os autores organizaram por finalidades os usos da avaliação externa como instrumento da gestão educacional nos estados, constituindo as seguintes categorias:

- avaliar e orientar a política educacional;

- informar as escolas sobre a aprendizagem dos alunos e definir as estratégias de formação continuada;

- informar ao público;

- alocar recursos;

- criar ou justificar políticas de incentivos salariais;

- compor a política de avaliação docente;

- certificar alunos e escolas.

Brooke e Cunha concluem que, apesar de os instrumentos terem melhorado tecnicamente ao longo do tempo e de haver maior confiabilidade nos resultados, eles continuavam sendo pouco aproveitados pelas secretarias de educação para a formulação de políticas de gestão: "os mesmos instrumentos estão sendo usados com objetivos diversos de modo que a 
finalidade precípua ou original do instrumento pouco esclarece sobre seus desdobramentos posteriores" (BROOKE; CUNHA, 2011, p. 20). Os autores enfatizam a fragilidade da avaliação externa como instrumento pedagógico e a dificuldade de se utilizarem os resultados da avaliação de forma mais produtiva do que se costuma fazer, na medida em que não se estabelece uma articulação entre eles, nem propostas curriculares organizadas e compartilhadas entre os professores.

A avaliação não deve ser tratada ou desenvolvida de forma isolada, mas sim como processo constitutivo do processo educativo em sua amplitude, ambos inseridos no projeto político pedagógico da instituição. Como argumentam Sousa e Oliveira (2003), "potencializar a dimensão educativa/formativa da avaliação certamente supõe a promoção da autonomia pedagógica e didática da escola e não a sua conformação" (p. 883). É preciso também considerar seus diferentes âmbitos: a aprendizagem, a experiência educativa oferecida em nível institucional e o sistema e suas políticas educacionais (FERNANDES; FREITAS, 2007).

Concordamos com Barretto quando observa:

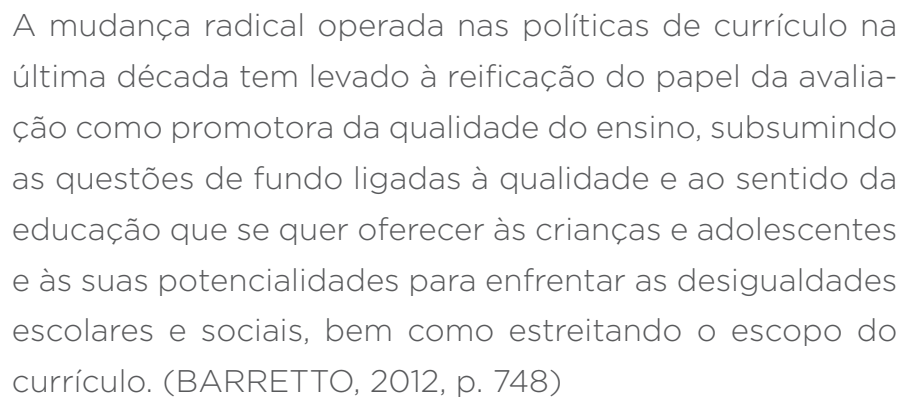

Assim como a autora, entendemos que a avaliação não ocupa a função de uma "panaceia educativa", sendo indispensável atentarmos para a inclusão de dimensões pedagógicas e socioculturais que configuram o fenômeno educativo e suas implicações nos processos de avaliação.

Rosemberg (2013), ancorada em pesquisas bibliográficas na área da educação que usaram o descritor "avaliação para educação infantil”, observa a baixíssima incidência deste na produção da área. ${ }^{5} \mathrm{~A}$ hipótese da autora é que essa ínfima produção localizada não significa "que o tema da
5 Rosemberg se baseia no trabalho de Senhorinha Paz (2005) e na própria pesquisa que realizou junto à coleção de textos deste periódico, e reafirma posições já manifestadas no estudo de Barretto et al. (2001). 
avaliação na educação infantil não tenha mobilizado gestores, pesquisadores(as) e ativistas da educação, mas sim que essa preocupação ainda não demarca um 'problema social' para integrar a agenda de política de avaliação na/da educação infantil”. No Brasil, segundo ela, ainda estamos iniciando a construção dessa agenda.

Na mesma linha de raciocínio de Rosemberg, propomos pensar a iminência desse novo "problema social" como um "mote crítico e propositivo" que tanto tensiona ideias e práticas estabelecidas na educação infantil como provoca uma ressignificação da relação entre avaliação, educação infantil e qualidade. $\mathrm{O}$ enfrentamento dessa questão, do nosso ponto de vista:

- exige e encoraja exercitar a qualificação do problema e pôr à prova os argumentos e as posições acerca da avaliação sedimentadas no campo da educação infantil;

- estimula a transpor temor e fobia ao tratar da avaliação para um comprometimento crítico e transformador da realidade;

- promove o estabelecimento de parcerias intra e extracontexto específico da educação infantil, na busca de encaminhamentos com instituições e demais setores sociais;

- provoca esforços de investigação e de estudos que tenham essa temática como centralidade;

- incita, numa perspectiva crítica, a articulação com experiências e propostas de avaliação, tanto em âmbito nacional como internacional;

- possibilita criar repertórios para gestores de instituições e de sistemas que qualificam as escolhas político-pedagógicas e as propostas avaliativas para educação infantil;

- amplia o debate acerca dos processos de avaliação e reconhece a importância da participação de diferentes interlocutores internos e externos à instituição educativa;

- colabora com a problematização sobre a qualidade da oferta da educação infantil às crianças pequenas. 
No Brasil, estamos percorrendo uma trajetória na educação infantil em que se busca o atrelamento entre qualidade e avaliação, o que pode der identificado em um conjunto de ações normativas e de políticas desde a década de 1990, mesmo antes da promulgação da Lei de Diretrizes e Bases da Educação Nacional de 1996 (BRASIL, 1996). Em 1995, o MEC publicou um documento de autoria de Fúlvia Rosemberg e Maria Malta Campos intitulado "Critérios para um atendimento em creches que respeite os direitos fundamentais das crianças" que instiga os envolvidos com a oferta de educação infantil, principalmente pública, a fazer uma reflexão sobre o conteúdo das políticas públicas e as práticas cotidianas em creches e pré-escolas, tendo como referência um conjunto de itens indicativos de uma boa educação, embasada no respeito aos direitos da criança (ROSEMBERG; MALTA, 1995). Mais do que um instrumento de avaliação da educação infantil, esse documento parece constituir uma orientação do que se deve considerar para garantir um serviço de qualidade às crianças.

O Plano Nacional de Educação (PNE), de 2001-2011, apresenta, entre suas metas, três ligadas à avaliação da oferta de educação infantil. A meta 10 indica que os municípios devem estabelecer um sistema de acompanhamento, controle e supervisão da educação infantil visando ao apoio técnico-pedagógico para a melhoria da qualidade e à garantia de cumprimento dos padrões mínimos estabelecidos pelas diretrizes nacionais e estaduais. A meta 11 propõe a criação de mecanismos de colaboração entre educação, saúde e assistência na manutenção, expansão, administração e avaliação das instituições de atendimento de crianças de 0 a 3 anos de idade. E a meta 19 estabelece parâmetros de qualidade dos serviços de educação infantil, como referência para a supervisão, controle e avaliação, e como instrumento para a adoção de medidas de melhoria da qualidade.

Há ainda outros documentos do Ministério da Educação, da década de 2000, que tratam da relação entre qualidade e educação infantil, sendo que alguns contêm proposições para o acompanhamento e monitoramento do que é oferecido às crianças. Entre esses documentos, vale mencionar: Política Nacional de Educação Infantil: pelo direito das crianças de zero 
a seis anos à educação (BRASIL, 2005); Parâmetros Nacionais de Qualidade para a Educação Infantil (BRASIL, 2006b); Parâmetros Básicos de Infraestrutura dos Estabelecimentos de Educação Infantil (BRASIL, 2006a); e Indicadores da Qualidade na Educação Infantil (BRASIL, 2009b).

No mesmo período, o Conselho Nacional de Educação (CNE) instituiu as Diretrizes Curriculares Nacionais para a Educação Infantil (BRASIL, 2009a), refletindo as aspirações da área, da sociedade civil, assim como as orientações da política nacional estabelecidas pela Secretaria de Educação Básica do MEC, através da Coordenação Geral de Educação Infantil. Ainda em 2009, o MEC lançou, em conjunto com a Unesco, o documento "Política de Educação Infantil no Brasil: relatório de avaliação” (BRASIL; ORGANIZAÇÃO DAS NAÇÕES UNIDAS PARA A EDUCAÇÃO, A CIÊNCIA E A CULTURA, 2009). E, em 2011, criou, através de portaria ministerial, um grupo de trabalho com a missão de produzir subsídios para a definição da política de avaliação em educação infantil no Brasil.

As discussões desse grupo resultaram no relatório "Educação Infantil: subsídios para a construção de uma sistemática de avaliação” (BRASIL, 2012), em que se define a avaliação como "atividade inerente à execução das políticas e programas, com potencial de produção de efeitos e de contribuição aos gestores do programa, coordenadores, docentes e beneficiários de suas ações, por meio de subsídios que apoiem o seu contínuo aprimoramento.” Diz o documento:

Concretizar tal perspectiva supõe a superação do caráter
meramente formal que muitas vezes assume a avaliação, em
que seus resultados não são utilizados para revisão ou re-
formulação de propostas e ações. O que se quer destacar
é que os processos de avaliação devem servir para induzir
ações, redirecionar trajetórias, subsidiar decisões e formular
políticas e planos. Esse processo reveste-se, no entanto, de
um caráter social, político e ideológico que, para se efetivar,
remete a construção de consensos. (BRASIL, 2012, p. 11)

Em consonância com os princípios discutidos nesse trabalho, vêm sendo realizados, desde 2010, alguns eventos que tratam da relação entre avaliação e qualidade para a etapa da 
educação infantil, promovidos (em parceria ou isoladamente) pelo MEC, pela Fundação Carlos Chagas e pelo Núcleo de Estudos e Pesquisas em Infância e Educação Infantil da Universidade Federal do Paraná (Nepie/UFPR). ${ }^{6}$ E desde 2013 está em curso o projeto Formação da Rede em Educação Infantil: Avaliação de Contexto, ${ }^{7}$ ao qual se vincula nosso objeto de estudo.

Neste artigo, pretendemos identificar o lugar da avaliação no campo da produção mais ampla sobre a educação infantil, examinar a natureza dos trabalhos e tipos de investigação realizada, por tema, objeto, instituições, período etc.

\section{ANÁLISE DA PRODUÇÃO BIBLIOGRÁFICA: PROCEDIMENTOS METODOLÓGICOS E PRIMEIROS INDICATIVOS}

Adentrar a discussão acerca da produção acadêmica sobre avaliação em educação infantil implicou a realização de um levantamento de trabalhos articulados a cursos de pós-graduação e organismos de pesquisa. A tipologia do material envolve teses, dissertações e artigos de periódicos. O período investigado, de 1997 a 2012, também delimitou o corpus empírico da pesquisa.

A justificativa da escolha a partir de 1997 deve-se ao fato de a atual LDB ter sido promulgada em dezembro de 1996, o que significou, em termos de estrutura da educação nacional, uma nova organização que incluiu a educação infantil como parte da educação básica, trazendo novas expectativas em relação às funções e identidade pedagógica dessa etapa. Outra delimitação para a composição do material de análise refere-se à possibilidade de obter textos na íntegra via internet.

A seguir, detalhamos os procedimentos que permitiram elencar o corpus empírico deste trabalho: base de dados, termos para a busca, procedimentos propriamente ditos e análises realizadas.

\section{SOBRE A BASE DE DADOS}

O corpus empírico deste estudo compõe-se de:

- teses e dissertações disponíveis na plataforma da Capes, ${ }^{8}$ realizadas no âmbito de programas de pós-graduação do país (universidades federais e estaduais);
6 Em 2010, a Fundação Carlos Chagas promoveu o Seminário Internacional sobre Qualidade na Educação Infantil. Em 2012, realizaram-se as seguintes atividades: Reunião Técnica na sede da Organização dos Estados Ibero-Americanos (OEI), promovida pelo MEC/OEI/UFPR; Seminário Internacional: Educação e Avaliação em Contextos da Educação Infantil, promovido pelo Nepie/UFPR; e Seminário Internacional Avaliação da Educação Infantil: Tendências e Perspectivas, pela Fundação Carlos Chagas. Em 2013, foram realizados o Seminário Internacional: Avaliação como Promoção da Qualidade: Política e Formação na Educação Infantil, promovido pelo Nepie/UFPR, e o II Seminário Internacional Avaliação da Educação Infantil: Tendências e Perspectivas, pela Fundação Carlos Chagas.

7 o projeto é coordenado nacionalmente pelas professoras Gizele de Souza e Catarina Moro. Envolve quatro universidades brasileiras - Universidade Federal do Paraná (UFPR) como proponente; Universidade Federal do Rio de Janeiro (UFRJ), Universidade Federal de Minas Gerais (UFMG) e a Universidade do Estado de Santa Catarina (Udesc), como participantes e colaboradoras - e duas universidades italianas - Università Degli Studi di Pavia (UNIPV) e Università degli Studi di Palermo (Unipa). E conta com apoio do Ministério da Educação, via projeto institucional de Cooperação Técnica com a Secretaria de Educação Básica (SEB) do Ministério. 
9 Endereços eletrônicos: $<$ http:// www.scielo.br/>; <http://educa.fcc. org.br/scielo.php>; <http://www. periodicos.capes.gov.br/>
- artigos em periódicos nacionais acessados via plataforma SciELO (Scientific Electronic Library Online), portal de periódicos da Capes e portal Educ@.9

\section{SOBRE AS PALAVRAS-CHAVE}

Com base em um levantamento prévio de descritores em algumas bases constatou-se que os termos de interesse da pesquisa não estavam presentes. Por isso, optou-se pela busca por palavras-chave pela possibilidade de selecionar um número maior de trabalhos. A construção do quadro de palavras-chave foi feita considerando a centralidade da educação da criança de 0 a 6 anos na nossa pesquisa e sua intersecção com a avaliação. A educação infantil foi tomada por sua definição legal: como primeira etapa da educação básica (artigo 29 da LDB), oferecida em creches e pré-escolas, entendidas como estabelecimentos educacionais públicos ou privados, não domésticos, regulados por órgão do sistema de ensino e submetido a controle social, conforme a Resolução CNE/CBE n. 05/09, que estabelece as diretrizes curriculares para a educação infantil.

Em relação à avaliação, a pesquisa assumiu uma perspectiva ampliada, visando a ter impacto na produção levantada. Assim, foram incluídas palavras-chave que permitissem identificar os trabalhos realizados em instituições de educação infantil ou relacionados a essa etapa da educação básica, e que indicassem como objeto do trabalho a discussão da qualidade da oferta desses serviços, em articulação ou não com procedimentos e instrumentos específicos de avaliação, seja das crianças, de seu aprendizado ou desenvolvimento, seja dos contextos de oferta, relativos à avaliação da experiência educativa das instituições, dos sistemas ou das políticas de educação infantil. Fez-se o cruzamento das palavras-chave 1 e 2, com o objetivo de identificar trabalhos em que houvesse a presença de ambas, - como mostra o Quadro 1. 
QUADRO 1 - Listagem dos dois tipos de palavras-chave utilizadas conjuntamente na seleção do material avaliado na pesquisa

\begin{tabular}{|l|l|}
\hline \multicolumn{1}{|c|}{ PALAVRAS-CHAVE 1 } & \multicolumn{1}{c|}{ PALAVRAS-CHAVE 2 } \\
\hline Educação infantil & Avaliação \\
Creche & Qualidade \\
Pré-escola & Autoavaliação \\
Crianças & Heteroavaliação \\
Crianças de o a 3 anos & Instrumentos de avaliação \\
Crianças de 4 a 6 anos & Doculas de avaliação \\
Infância & Portfólio \\
& Registróa pedagógica \\
& Registro pedagógico \\
& Parecer descritivo \\
& Ficha avaliativa \\
\hline
\end{tabular}

Fonte: Elaboração das autoras com base nos dados levantados para a presente pesquisa.

\section{SOBRE OS PROCEDIMENTOS}

Por intermédio das bases de dados já mencionadas, foi possível levantar os resumos das teses e dissertações, bem como os artigos na íntegra. A leitura dos títulos, resumos e palavras-chave indicaram a aderência ou não aos termos indicados. Em seguida, para os materiais que compuseram o corpus da pesquisa, foi feita a análise dos trabalhos obtidos na íntegra.

A exclusão de trabalhos dessa amostra se deu em função de:

- a etapa de ensino considerada na pesquisa/artigo não tratar da educação infantil;

- o tema da avaliação estar desvinculado do locus educativo da oferta, que é a educação infantil (foram identificadas várias produções abordando a avaliação de crianças pequenas, com base em aspectos cognitivos ou comportamentais, em áreas específicas ou não, mas não relacionadas ao trabalho pedagógico da instituição educativa);

- a questão principal do trabalho encontrado, ainda que fizesse uso de registros e de outras formas de documentação, não dizer respeito à análise das práticas educativas realizadas em contextos institucionais ou políticos, nem à apreciação do resultado do processo educativo;

- não ter sido possível o acesso ao texto integral pela via digital.

Considera-se, entre as finalidades do exame dessa produção, identificar:

- a composição final da amostra; 
- o objeto dos estudos (predominância em relação à avaliação da criança ou à avaliação de contexto institucional, do sistema ou das políticas);

- a natureza da base empírica (pesquisa de campo/ empírica, ensaio, pesquisa bibliográfica, pesquisa documental etc.);

- a área de conhecimento na qual a pesquisa se insere;

- a vinculação institucional que originou os trabalhos;

- período de maior ou menor incidência de trabalhos sobre a temática;

- questões relativas a instrumentos de avaliação utilizados ou discutidos e considerações dos trabalhos examinados.

\section{COMPOSIÇÃO DA AMOSTRA}

A composição total da amostra é de 66 trabalhos, sendo 7 teses, 35 dissertações e 24 artigos. No banco da Capes, foram encontradas 46 dissertações, todas defendidas até o ano de 2006; contudo, 11 não estavam disponíveis integralmente.

Quanto aos artigos, a maioria não se refere diretamente ao objeto da tese ou dissertação do autor ou de um dos autores, mas tem relação com a temática de pesquisas do orientador ou do grupo de investigação ao qual o autor estava vinculado enquanto aluno da pós-graduação ou pesquisador em outros espaços de estudos.

\section{OBJETO DOS ESTUDOS}

Entre as teses, observou-se uma proporção maior de estudos de avaliação das crianças, com 4 pesquisas, comparativamente à avaliação de contexto, com 3 trabalhos.

No caso das dissertações, a situação se inverte: foram encontrados 18 trabalhos sobre a avaliação de contexto e 11 sobre a avaliação das crianças. E ainda, 6 que contemplam os dois aspectos.

No tocante aos artigos, 17 são sobre avaliação de contexto, relativos à avaliação institucional ou à avaliação de sistemas e políticas públicas para a educação infantil; 5 tratam da avaliação das crianças; e 2 contemplam os dois aspectos.

A partir desses dados, fica evidente a maior proporção de estudos de contexto na temática da avaliação, o que 
reafirma a preocupação recente com a interface entre qualidade, educação infantil e avaliação. Outro aspecto a destacar é que, apesar natureza diversa dos trabalhos de avaliação de contexto (empíricos, ensaísticos, bibliográficos, documentais), estes abordam principalmente a avaliação das interações entre as crianças e entre crianças e adultos e a avaliação de práticas educativas no interior das turmas nas instituições educacionais.

\section{NATUREZA DOS TRABALHOS}

A amostra pesquisada constitui-se de 52 estudos de campo, sendo 5 entre as teses de doutorado, 33 entre as dissertações de mestrado e 14 artigos. Em número muito menor, a amostra inclui pesquisa documental em todos os segmentos, sendo 2 teses, 2 dissertações e 1 artigo. Entre os artigos encontram-se, ainda, 8 ensaios e um 1 trabalho de revisão bibliográfica. A maior parte dos trabalhos refere-se a pesquisas de campo, compreendendo estudos de caso e pesquisas quantitativas que utilizam escalas de avaliação.

A pesquisa bibliográfica, único trabalho dessa natureza, analisa a produção bibliográfica nacional sobre qualidade na educação infantil entre 1996 e 2003. Os 5 trabalhos de pesquisa documental analisam e buscam a articulação entre documentos nacionais e internacionais acerca da qualidade dos processos avaliativos na educação infantil ou analisam documentos do contexto pesquisado, instituição ou sistema/ rede municipal de ensino. $\mathrm{E}$ os 8 ensaios discutem as finalidades das proposições sobre avaliação, sua relação com a qualidade; um deles analisa um determinado instrumento avaliativo.

\section{INSTITUIÇÕES DE ORIGEMEÁREA DE CONHECIMENTO EM QUE SE INSEREM OS TRABALHOS DE MESTRADO E DOUTORADO}

A distribuição das pesquisas de doutorado, concretizadas em teses defendidas sobre a temática deste estudo, estão concentradas em 5 instituições, entre as quais a Universidade de São Paulo (USP) responde por 4 das 7 levantadas (uma delas é do campus de Ribeirão Preto, na área da psicologia, e as 
outras três do campus de São Paulo, na área da educação). As outras 3 teses, todas na área de educação, foram defendidas, respectivamente, na Universidade Estadual Paulista "Júlio de Mesquita Filho” (Unesp), campus de Marília, na Universidade Federal do Ceará (UFC) e na Universidade Estadual de Campinas (Unicamp).

TABELA 1 - Distribuição dos trabalhos de pós-graduação em nível de doutorado

\begin{tabular}{l|c|c} 
& \multicolumn{2}{|c}{ ÁREA DE CONHECIMENTO } \\
\hline INSTITUIÇÃO DE ORIGEM & EDUCAÇÃo & PSICOLOGIA \\
\hline USP - SP & 3 & 1 \\
\hline USP - Ribeirão Preto & & 1 \\
\hline Unesp - Marília & 1 & \\
\hline Unicamp & 1 & 1 \\
\hline UFC & 1 & \\
\hline TOTAL & 6 & \\
\hline
\end{tabular}

Fonte: Elaboração das autoras com base nos dados levantados para a presente pesquisa.

Considerando-se os trabalhos de mestrado defendidos, em número significativamente maior que os de doutorado, temos um elenco bastante diversificado de instituições nas quais as pesquisas foram propostas e defendidas. Ainda assim, observa-se uma concentração maior em 2 instituições - Universidade do Vale do Itajaí (Univali) e Universidade de Brasília (UnB), com 7 e 6 dissertações, respectivamente. Três outras instituições respondem por 6 pesquisas, sendo 2 da Universidade Federal de Santa Catarina (UFSC), 2 da Universidade Estadual de Campinas (Unicamp) e 2 da Pontifícia Universidade Católica de São Paulo (PUC-SP). 
TABELA 2 - Distribuição dos trabalhos de pós-graduação em nível de mestrado

\begin{tabular}{|c|c|c|c|}
\hline \multirow[b]{2}{*}{ INSTITUIÇÃO DE ORIGEM } & \multicolumn{3}{|c|}{ ÁREA DE CONHECIMENTO } \\
\hline & EDUCAÇÃO & PSICOLOGIA & OUTRAS \\
\hline Univali & 7 & & \\
\hline UnB & 6 & & \\
\hline UFSC & 2 & & \\
\hline Unicamp & 2 & & \\
\hline USP Ribeirão Preto & & 1 & \\
\hline USP SP & 1 & & \\
\hline Centro Univ. Anápolis & 1 & & \\
\hline PUC SP & 1 & & 1 \\
\hline PUC Rio & & 1 & \\
\hline PUC Campinas & 1 & & \\
\hline PUC PR & 1 & & \\
\hline UFPI & 1 & & \\
\hline Udesc & 1 & & \\
\hline Mackenzie & & & 1 \\
\hline UFC & 1 & & \\
\hline UFMS & 1 & & \\
\hline UFMG & & 1 & \\
\hline UFJF & 1 & & \\
\hline UEL & 1 & & \\
\hline UFF & 1 & & \\
\hline UFSCar & & & 1 \\
\hline TOTAL & 28 & 4 & 3 \\
\hline
\end{tabular}

Fonte: Elaboração das autoras com base nos dados levantados para a presente pesquisa.

A pertinência à determinada área de conhecimento foi considerada somente para as pesquisas de pós-graduação, e não para os artigos. Observa-se que, na composição dessa subamostra, a área da educação é predominante, com 28 estudos. Segue-se a área de psicologia, com 4 estudos, e outros 3 de áreas distintas, sendo 1 da área de ciências biológicas/saúde, 1 ligado à sociedade, tecnologia e meio ambiente e 1 sobre educação especial. É interessante assinalar que, apesar da predominância da educação como área originária dos estudos de 
pós-graduação, muitos pesquisadores são egressos de outras áreas, como a psicologia.

\section{PERIÓDICOS PESQUISADOS}

TABELA 3 - Distribuição dos artigos avaliados na pesquisa

\begin{tabular}{|c|c|c|c|}
\hline \multirow[b]{2}{*}{ PERIÓDICO } & \multicolumn{3}{|c|}{ ÁREA DE CONHECIMENTO } \\
\hline & EDUCAÇÃO & PSICOLOGIA & OUTRA \\
\hline Cadernos de Pesquisa & 5 & & \\
\hline $\begin{array}{l}\text { Estudos em Avaliação } \\
\text { Educacional }\end{array}$ & & & 4 \\
\hline Paidéia & 2 & & \\
\hline Contrapontos & & 2 & \\
\hline Educação e Pesquisa & 1 & & \\
\hline $\begin{array}{l}\text { Ensaio: Avaliação e Políticas } \\
\text { Públicas em Educação }\end{array}$ & 1 & & \\
\hline Psicologia: Teoria e Pesquisa & 1 & & \\
\hline Psicologia Escolar e Educacional & 1 & & \\
\hline Psicologia em Estudo & 1 & & \\
\hline Revista Brasileira de Educação & 1 & & \\
\hline Revista Diálogo Educacional & & 1 & \\
\hline Acta Scientiarum. Education & & 1 & \\
\hline Educação: Teoria e Prática & & 1 & \\
\hline Em aberto & & 1 & \\
\hline TOTAL & 13 & 7 & 4 \\
\hline
\end{tabular}

Fonte: Elaboração das autoras com base nos dados levantados para a presente pesquisa

Entre os periódicos que dispõem de artigos referentes à discussão de qualidade e avaliação em educação infantil verificamos que 4 contêm mais da metade das publicações encontradas: 13 artigos foram publicados em Cadernos de Pesquisa, Estudos em Avaliação Educacional, Paidéia e Contrapontos. Os outros 11 artigos estão distribuídos um em cada periódico. 


\section{PERÍODO DE MAIOR OU MENOR INCIDÊNCIA}

A busca foi feita a partir de 1997, porém, não localizamos nenhuma produção nesse ano, o que nos permitiu reunir a incidência dos trabalhos em três grupos com intervalo de cinco anos.

Assim, em relação às teses, no período de 1998 a 2002, não encontramos nenhuma; entre 2003 e 2007, foram apenas 2; e, entre 2008 e 2012, foram 5.

Quanto aos estudos resultantes de mestrado encontramos, entre 1998 e 2002, 2 dissertações; entre 2003 e 2007, o número elevou-se para 15; e, entre 2008 e 2012, para 18.

QUADRO 2 - Distribuição dos trabalhos analisados na pesquisa segundo $o$ ano de publicação

\begin{tabular}{|c|c|c|c|}
\hline ANO & ARTIGOS & DISSERTAÇÕES & TESES \\
\hline 1998 & 1 & - & - \\
\hline 1999 & 1 & - & - \\
\hline 2000 & - & 1 & - \\
\hline 2001 & 1 & - & - \\
\hline 2002 & - & 1 & - \\
\hline 2003 & 2 & 1 & 1 \\
\hline 2004 & 3 & 2 & - \\
\hline 2005 & 2 & 2 & - \\
\hline 2006 & 3 & 4 & 1 \\
\hline 2007 & 1 & 6 & - \\
\hline 2008 & 1 & 3 & 2 \\
\hline 2009 & 1 & 6 & 1 \\
\hline 2010 & 3 & 5 & 1 \\
\hline 2011 & 4 & 3 & 1 \\
\hline 2012 & 1 & 1 & - \\
\hline TOTAL & 24 & 35 & 7 \\
\hline
\end{tabular}

Fonte: Elaboração das autoras com base nos dados levantados para a presente pesquisa.

Entre os artigos que compõem a amostra pesquisada, o maior número de publicações é referente ao período de 2003 a 2007, totalizando 11. No período de 1998 a 2002, registram-se 3 artigos; e, entre 2008 a 2012, 10 artigos. Em percentual, a produção entre 1998 a 2002 corresponde a 12,5\%; entre 2003 a 2007, a 45,83\%; e entre 2008 a $2012,41,66 \%$. 
Já considerando a publicação inerente aos cursos de pós-graduação, tem-se o percentual de 5,71, entre 1998 a 2002, relativo a 2 dissertações defendidas. Entre 2003 a 2007, foram 15 dissertações, o que corresponde a $42,86 \%$ do total da produção de mestrado, e entre 2008 a 2012, as 18 dissertações perfazem $51,43 \%$.

Para as teses não há registro entre 1998 a 2002; no período de 2003 a 2007, registram-se 2 e, entre 2008 a 2012, 5 teses. Percentualmente há dois grupamentos: entre 2003 a 2007 concentram-se $28,57 \%$; e entre 2008 a $2012,71,43 \%$ das teses produzidas sobre o tema.

Esses números mostram que a temática da avaliação tem suscitado maior interesse nos últimos dez anos. Uma hipótese passível de ser formulada para explicar tais números relaciona-se a dois fatores:

- Um de caráter organizacional e pedagógico da área, junto aos sistemas de ensino. Pois, quanto mais a educação infantil passa a ser regulada e normatizada por estar integrada aos sistemas de ensino e, por consequência, objeto de orientações pedagógicas diversas, mais requer investimento em estudos sobre a interface entre avaliação, qualidade, proposta pedagógica e direito à educação das crianças pequenas.

- Outro de natureza político-acadêmica, em relação ao lugar da avaliação no debate nacional. Temos presenciado nos últimos anos proposições de avaliação da criança como aferição e intervenção no combate à pobreza no âmbito do governo federal e de alguns estados e municípios. Em reação a tais proposições, pesquisadores e militantes da área de educação infantil, e o próprio Ministério da Educação, vêm produzindo orientações e estudos no intuito de reafirmar o lugar da avaliação na especificidade da área da educação - o que não deve implicar a avaliação de crianças e professores. 
INSTRUMENTOS DE AVALIAÇÃO PRESENTES NOS TRABALHOS ANALISADOS

Em relação a instrumentos relativos ao processo avaliativo utilizados nos estudos, dos 66 trabalhos, 10 utilizam escalas norte-americanas ITERS (ITERS-R) e ECERS (ECERS-R), seja no âmbito da aplicação ou mesmo da discussão acerca de sua aplicabilidade no país. Pelo menos 1 trabalho utiliza um instrumento australiano, o QIAS (acerca do credenciamento e melhoria da qualidade de creches, produzido pelo Conselho Nacional de Credenciamento de Creches da Austrália e adaptado para utilização no Brasil por Piotto et al. (1998). E outros 3 trabalhos utilizam escalas de empenho do adulto e envolvimento das crianças de Ferre-Leavers. Outros trabalhos individuais fizeram uso do: formulário de registro das atividades de Pascal et al., adaptado por Cordeiro e Benoit (2004); da escala de interação professor-criança de Farran e Collins; do ASQ- ${ }^{10}$ (não constam nomes de profissionais responsáveis pela tradução e adaptação no Brasil); do instrumento Child Care Facility Schedule (CCFS, instrumento desenvolvido por um grupo colaborativo da Organização Mundial de Saúde e traduzido para o português, em Portugal, como Escala de Avaliação de Estabelecimentos Prestadores de Cuidados a Crianças, por Pedro Caldeira da Silva); e dos Indicadores da Qualidade na Educação Infantil (BRASIL, 2009b).
$10 \bigcirc$ Ages and Stages Questionaire (ASQ-3) é um instrumento de triagem acerca de problemas ou distúrbios no desenvolvimento de crianças pequenas na faixa etária de 1 a 66 meses de idade, com vistas ao encaminhamento, se necessário, a um profissional especializado. Investiga cinco dimensões do desenvolvimento infantil: comunicação, motora ampla, motora fina, solução de problemas, pessoal/social e emocional, informando em qual daquelas dimensões a criança está menos desenvolvida. São 21 escalas, sendo que cada uma contém 30 perguntas; como existem repetições, o total de itens não repetidos é 275 . O ASQ-3 classifica as crianças em três categorias: (a) necessita uma avaliação em profundidade; (b) monitoramento e estímulos adicionais são recomendados; e (c) está-se desenvolvendo conforme esperado. 
Quadro 3 - Instrumentos referenciados/utilizados nos trabalhos avaliados na pesquisa

\begin{tabular}{|l|c|}
\hline \multicolumn{1}{|c|}{ INSTRUMENTO } & QUANTIDADE \\
\hline Escalas ITERS (ITERS-R) e ECERS (ECERS-R) & 10 \\
\hline Escala QIAS & 3 \\
\hline Escalas de Ferre-Leavers & 1 \\
\hline Formulário de Pascal e cols & 1 \\
\hline Escala de Farran e Collins & 1 \\
\hline Escala ASQ-3 & 1 \\
\hline Escala Child Care Facility Schedule (CCFS) & 1 \\
\hline Indicadores da Qualidade na Educação Infantil & 1 \\
\hline
\end{tabular}

Fonte: Elaboração das autoras com base nos dados levantados para a presente pesquisa.

Outros trabalhos optaram por utilizar roteiros de observação, questionários e entrevistas. Em 1 caso faz-se a proposição de um instrumento de avaliação para verificar a mediação do adulto com as crianças.

\section{CONSIDERAÇÕES ACERCA DOS TRABALHOS EXAMINADOS}

Apesar de os trabalhos desta pesquisa bibliográfica indicarem a avaliação de contexto com maior presença, enquanto a avaliação da criança vem sendo menos tematizada na área; depreendemos que esta última se faz muito presente no cotidiano das instituições de educação infantil brasileiras, assim como no âmbito da gestão municipal.

A avaliação da criança é tematizada prioritariamente na perspectiva de análise das práticas avaliativas correntes no cotidiano das instituições, desvelando críticas a determinadas formas classificatórias de avaliação e destacando o portfólio como referência a um processo avaliativo “ideal” na educação infantil. Percebemos que o portfólio ora constitui-se em objeto de estudo, ora em recomendação pedagógica. 
Foram agrupados e nomeados, na categoria "avaliação de contexto", os trabalhos que incidiam acerca de avaliação institucional, das concepções do professor sobre qualidade, em uma perspectiva mais específica, como, por exemplo, relativa a estudos do interior das turmas de crianças, considerando-se as práticas educativas e as interações ali presentes.

Identificamos na produção aqui levantada menor incidência de estudos que tomam a ideia de contexto imbricado em outros aspectos, tais como gestão da instituição, formação continuada, relacionamento entre a instituição e as famílias, articulação das práticas educativas com outros níveis da gestão e políticas municipais ou mesmo nacionais.

Por fim, vale ressaltar que neste exercício analítico (em curso) da produção brasileira sobre avaliação em educação infantil, é imprescindível estarmos atentos para algumas questões como a:

- necessidade do refinamento acerca do que se tem denominado "avaliação da" e "na educação infantil" e os respectivos usos conceituais e políticos entre essas diferenciações;

- consideração de que a diferenciação acima pode estar a serviço de fins didáticos, todavia, há uma complexidade na qual a avaliação de contexto pode, ao nosso juízo, problematizar a avaliação da criança. Dito de outro modo, seria pensarmos que a avaliação da educação infantil se entremeia à avaliação na educação infantil;

- análise dos aportes teóricos que têm embasado os estudos e instrumentos de avaliação em educação infantil, como princípios, conceitos, metodologias, finalidades referidas e apropriadas.

\section{AVALIAÇÃO EM EDUCAÇÃO INFANTIL: PROPÓSITOS E QUESTÕES FINAIS}

Para finalizar, entendemos que é oportuno demarcar, ainda que sumariamente, alguns propósitos e questões acerca da temática da avaliação que nos parecem relevantes neste debate. Cientes de que o olhar analítico não é desprovido das 
11 As pesquisadoras de Pavia, com as quais temos dialogado, são as doutoras Egle Becchi, Anna Bondioli, Monica Ferrari e Donatella Savio. escolhas teórico-metodológicas, pensamos a avaliação com base nos estudos das pesquisadoras italianas da Università Degli Studi di Pavia ${ }^{11}$ (BECCHI, 2004; BONDIOLI, 2004, 2006, 2010; BONDIOLI; FERRARI, 2008; BONDIOLI; SAVIO, 2010, 2013; SAVIO, 2011), produção que nos auxilia no registro dos seguintes apontamentos: o caráter político e a não neutralidade do processo avaliativo, por considerar a natureza construída dos dados avaliativos e situada quanto ao objeto da avaliação; a perspectiva democrática e participativa da avaliação, por meio do debate e confronto de ideias entre os envolvidos e interessados na instituição educativa e da ação sinérgica a partir de acordos e consensos construídos; a concepção de avaliação como uma prática que permite à instituição educativa refletir sobre si, sobre sua identidade, verificando e consolidando consensos acerca de seu próprio projeto; a ênfase ao caráter formativo da avaliação de determinado contexto, o que potencializa a criação de percursos de melhorias, em detrimento do juízo final acerca dos resultados. O destaque a ser feito aqui diz respeito ao entrelaçamento de várias dimensões e níveis de atuação, como: a maior consciência dos profissionais acerca do seu trabalho em relação aos propósitos das práticas educativas; o agir educativo com mais intencionalidade; o empowerment profissional, não apenas individual, mas sobretudo coletivo, do grupo que se envolve nesse trabalho autoavaliativo; os instrumentos a serem utilizados para avaliar determinado contexto, que devem contar com a validação consensual dos envolvidos, independentemente de se tratar de instrumentos já existentes ou de instrumentos a serem construídos ad hoc; o processo avaliativo como percurso continuado e a necessidade de apoio "externo", com funções de mediação; enfim, procedimentos avaliativos que incluam o diálogo, o debate e a negociação, reconhecendo conflitos potenciais quanto aos interesses dos sujeitos envolvidos como necessários nessa direção. Avaliar convoca aqueles que, por razões diversas, se sensibilizam e se comprometem com a saúde e o "bem-estar" de uma instituição, o que nos permite pensar em uma "ética da responsabilidade" (BONDIOLI; FERRARI, 2000, p. 21). 


\section{REFERÊNCIAS}

BARRETTO, Elba Siqueira de Sá. Políticas de currículo e avaliação e políticas docentes. Cadernos de Pesquisa, São Paulo, n. 147, p. 738-753, 2012.

BARRETTO, Elba Siqueira de Sá et al. Avaliação na educação básica nos anos 90 segundo os periódicos acadêmicos. Cadernos de Pesquisa, São Paulo, n. 114, p. 49-88, 2001.

BECCHI, Egle. A qualidade das redes educativas e suas derivações: projeto, sistema, verificação. In BONDIOLI, Anna. (Org.). 0 projeto pedagógico da creche e a sua avaliação: a qualidade negociada. Campinas: Autores Associados, 2004. p. 59-64.

BONDIOLI, Anna. Valutare. In: BONDIOLI, Anna; FERRARI, Monica (Org.). Verso un modello di valutazione formativa: ragione, strument e percorsi. Bologna: Junior, 2004. p. 11-58.

. Riflettere sul contesto e le pratiche educative: un modello di evaluation formativa. In: COMUNE DI GENOVA, GRUPPO NAZIONALE NIDI INFANZIA. Le culture dell'infanzia. Bologna: Junior, 2006. p. 159-178.

. Valutare per riflettere: un approccio partecipativo. Infanzia, v. 5, p. 329-332, 2010.

BONDIOLI, Anna; FERRARI, Monica (Org.). Manuale di valutazione de contesto educativo: teorie, modelli, studi per la rilevazione della qualità della scuola. Milano: Franco Angeli, 2000.

Verso un modello di valutazione formativa. Bologna: Junior, 2004.

. AVSI, AutoValutazione della Scuola dell'Infanzia. Uno strumento di formazione e il suo collaudo. Bologna: Junior, 2008.

BONDIOLI, Anna; GHEDINI, Patrizia (Org.). 0 projeto pedagógico da creche e a sua avaliação: a qualidade negociada. Campinas: Autores Associados, 2004.

BONDIOLI, Anna; SAVIO, Donatella. Introduzione. In: BONDIOLI, Anna; SAVIO, Donatella (Org.). Partecipazione e qualità: percorsi di condivisione riflessiva nei servizi per l'infanzia di Modena. Parma, IT: Junior, 2010. p. 9-13.

BONDIOLI, Anna; SAVIO, Donatella (Org.). Partecipazione e qualità: percorsi di condivisione riflessiva nei servizi per l'infanzia di Modena. Parma, IT: Junior, 2010.

BONDIOLI, Anna; SAVIO, Donatella (Org.). Participação e qualidade em educação da infância: percursos de compartilhamento reflexivo em contextos educativos. Tradução: Luiz Ernani Fritoli. Curitiba: Editora UFPR, 2013.

BRASIL. Lei n. 9.394, de 20 de dezembro de 1996. Estabelece as diretrizes e bases da educação nacional. Brasília, DF, 1996.

BRASIL. Ministério da Educação. Educação Infantil: subsídios para a construção de uma sistemática de avaliação. Documento produzido pelo Grupo de Trabalho instituído pela Portaria n. 1.147/2011. Brasília: MEC/SEB, 2012.

Secretaria de Educação Básica. Política Nacional de Educação Infantil: pelo direito das crianças de zero a seis anos à educação. Brasília, DF: MEC/ SEB, 2005. 
. Parâmetros Básicos de Infraestrutura para Instituições de Educação Infantil. Brasília: MEC/SEB, 2006a.

Parâmetros Nacionais de Qualidade para a Educação Infantil. Brasília: MEC/ SEB, 2006b.

. Diretrizes Curriculares Nacionais para a Educação Infantil. Brasília: MEC/ SEB, 2009a.

. Indicadores da Qualidade na Educação Infantil. Brasília: MEC/SEB, 2009b.

BRASIL. Ministério de Educação; ORGANIZAÇÃO DAS NAÇÕES UNIDAS

PARA A EDUCAÇÃO, A CIÊNCIA E A CULTURA. Política de Educação no Brasil: relatório de avaliação 2009. Brasília, DF: MEC/Unesco, 2009.

BROOKE, Nigel; CUNHA, Maria Amália de Almeida. Avaliação externa como instrumento da gestão educacional nos estados. Estudos e Pesquisas Educacionais, São Paulo, n. 2, p. 17-79, 2011.

CORDEIRO, Maria Helena; BENOIT, Jaqueline. Centros de educação infantil como contextos de desenvolvimento: utilizando o nível de envolvimento nas atividades para avaliar o processo de aprendizagem. Contrapontos, v. 4, n. 1, p. 189-211, jan./abr. 2004.

FERNANDES, Cláudia de Oliveira; FREITAS, Luiz Carlos de. Indagações sobre currículo: currículo e avaliação. Brasília, DF: MEC/SEB, 2007.

MORO, Catarina. Produção brasileira sobre a avaliação e educação infantil: tendências. Revista Latinoamericana de Educação Infantil, v. 2, n. 2, p. 53-67, jul. 2013.

NEVES, Vanessa Ferraz Almeida; MORO, Catarina. Avaliação na Educação Infantil: um debate necessário. Estudos em Avaliação Educacional, São Paulo, v. 24 , n. 55, p. 272-302, abr./ago. 2013.

PAZ, Senhorinha de Jesus. A avaliação na educação infantil: análise da produção acadêmica brasileira presente nas reuniões anuais da ANPEd entre 1993 e 2003. Dissertação (Mestrado em Educação) - Universidade Federal de Santa Catarina, Florianópolis. 2005.

PIOTTO, Débora Cristina et al. Promoção da qualidade e avaliação na educação infantil: uma experiência. Cadernos de Pesquisa, São Paulo, n. 105, p. 52-77, nov. 1998.

ROSEMBERG, Fúlvia. Políticas de educação infantil e avaliação. Cadernos de Pesquisa, São Paulo, v. 43, n. 148, p. 44-75, jan./abr. 2013.

ROSEMBERG, Fúlvia; CAMPOS, Maria Malta. Critérios para um atendimento em creches que respeite os direitos fundamentais das crianças. Brasília: MEC/SEF/ COEDI, 1995.

SAVIO, Donatella. Il gioco e l'identità educativa del nido d'infanzia: un percorso partecipato dei nidi di Modena. Parma, IT: Junior, 2011.

SOUSA, Sandra Maria Zakia Lian. Avaliação da aprendizagem: ênfases presentes na pesquisa no Brasil de 1930 a 1980. Cadernos de Pesquisa, São Paulo, v. 94, p. 43-49, 1995. 
SOUSA, Sandra Maria Zakia Lian; OLIVEIRA, Romualdo Portela de. Políticas de avaliação da educação e quase mercado no Brasil. Educação e Sociedade, Campinas, v. 24, n. 84, p. 873-895, 2003.

\section{CATARINA MORO}

Professora do Setor de Educação da Universidade Federal do Paraná. Pesquisadora do Núcleo de Estudos e Pesquisas em Infância e Educação Infantil (Nepie/UFPR)

moro.catarina@gmail.com

\section{GIZELE DE SOUZA}

Professora do Setor de Educação e do Programa de Pós-Graduação em Educação da Universidade Federal do Paraná (UFPR).

Coordenadora do Núcleo de Estudos e Pesquisas em

Infância e Educação Infantil (Nepie/UFPR)

gizelesouza@uol.com.br 